\title{
Interactive comment on "Seabed images from Southern Ocean shelf regions off the northern Antarctic Peninsula and in the southeastern Weddell Sea” by Dieter Piepenburg et al.
}

Dieter Piepenburg et al.

dieter.piepenburg@awi.de

Received and published: 28 May 2017

\section{Dear Sir/Madam,}

Thank you very much for your comments on our submission to ESSD. We appreciate your positive review and have modified the ms according to your suggestions:

p 2, I 15 : "In addition, they contribute to biogeochemical cycling, e.g. recycling of nutrients and sequestration of carbon and silicate." This sentence is very general and can hold true for all types of organism and community. I am not sure it is really needed here. REPLY: We have omitted this superfluous sentence. 
is no consistency in symbols and appearance between figures 2 and 4 (station maps). In addition, in figure 2 some stations are hardly distinguished between each other. This could be improved. REPLY: We modified Figure 2. Its appearance is now very similar to Figure 4, particularly with regard to the station symbols that are now the same in both figures.

(2) Some transect data are missing in table 1 compared to table 2: transect length and associated number of photos. REPLY: We added transect lengths and associated numbers of photos to Table 1.

We acknowledge that the changes you proposed were helpful for improving the manuscript. We hope that the revised version is now ready for publication. And we are looking forward that our paper will contribute to informing the scientific community about the public availability of Southern Ocean seabed image data, which will then hopefully analysed in ways beyond what we did so far, we are planning to do - and we can likely imagine.

On the behalf of all authors, Dieter Piepenburg

Interactive comment on Earth Syst. Sci. Data Discuss., doi:10.5194/essd-2017-18, 2017. 